\title{
ANCESTRAIS, TARTARUGAS E MOISÉS - INTERFACE DIALÓGICA ENTRE ARQUEOLOGIA E ANTROPOLOGIA NA ETNOGRAFIA DOS HUPD'ÄH (RIO NEGRO)
}

Ancestors, Turtles and Moses - Dialogic Interface Between Archaeology and Antropology in Hupd'äh Ethnography (Rio Negro)

Ancestrales, Tortugas y Moisés - Interface Dialógica entre la Arqueología y Antropología en la Etnografía de los Hupd'äh (Rio Negro)

Frederic M. C. Pouget ${ }^{1}$ Danilo P. Ramos ${ }^{2}$

\section{RESUMO}

O artigo visa problematizar a noção de ancestralidade, recurso conceitual comum aos temas de patrimônio e à interpretação arqueológica. Para tanto, utilizamos aportes teóricos da antropologia e da arqueologia em diálogo com a experiência etnográfica junto aos Hupd'äh Maku (Alto Rio Negro). Esse povo parece associar um aspecto de ancestralidade da mitologia bíblica judaica cristã às sua própria noção de ancestralidade. Pretende-se demonstrar como os contextos arqueológicos associados etnograficamente podem complexificar as noções de patrimônio (material e imaterial) e de ancestralidade.

Palavras-chave: Ancestralidade; Etnoarqueologia; Hupd'äh, Maku.

\section{ABSTRACT}

Nowadays, the notion of ancestry is very important to archeological and patrimonial debates. This article focus on the Hupd'äh (Alto Rio Negro region) perception of ancestry. With archeological and anthropological approaches, we try to understand the complex appropriation of aspects of the Judaic Cristian biblical mythology made by these people. We try to show that the ethnographical association of archeological contexts could complexify the patrimonial (material and immaterial) and ancestry notions.

Keywords: Ancestrality; Ethnoarchaeology; Hupd'äh, Maku

\section{RESUMEN}

Ese trabajo pretende problematizar la noción de ancestralidad, común a los debates arqueológicos y de patrimonio. Para esto, utilizamos aportes teóricos de la antropología y de la arqueología en diálogo con la experiencia etnográfica con los Hupd'äh - Maku (Alto Rio Negro). Ese pueblo indígena mescla percepciones de la mitología judaica cristiana bíblica a sus propias concepciones de ancestralidad. Los contextos arqueológicos, asociados etnográficamente, pueden complejizar las nociones de patrimonio (material e inmaterial) y de ancestralidad.

\footnotetext{
${ }^{1}$ Doutorando em História Cultural- IFCH/UNICAMP, Mestre em Arqueologia- MAE/USP, Bacharel em Ciências Sociais- USP. (Pouget@yahoo.com)

${ }^{2}$ Doutor em Antropologia Social- USP, Mestre em Antropologia Social- USP, Bacharel em Ciências SociaisUSP. (danilo.ramos@usp.br)
} 
Palabras clave: Ancestralidad; Etnoarqueología; Hupd’äh, Maku

\section{Introdução}

Tendo como base a experiência etnográfica junto aos Hupd'äh na bacia do Alto Rio Negro (AM), visamos explorar o contexto antropológico através do qual a cultura material arqueológica é acionada pela população indígena e integrada em sua matriz cultural. Tal matriz é permeada por diversos processos sociais e históricos que variam desde a compreensão de cultura per se como por pressões sócio-políticas históricas ou até mesmo por contextos ontológicos da cultura material (ALBERTI et al. 2001; POUGET, 2010) decorrente do contato com a sociedade envolvente.

Nesse sentido, o intuito desse artigo é problematizar, portanto, uma categoria conceitual que passa despercebida nos escritos de arqueologia: a ancestralidade. Isso não significa que não existam trabalhos de profunda reflexão sobre o tema, mas é comum uma forte generalização das referências temporais baseadas em um olhar deveras etnocêntrico (FAUSTO \& HECKENBERGER, 2007; BENJAMIN, 1992; LYDON \& RIZVI, 2010). Como veremos, a noção de ancestralidade mostra-se especialmente relevante para o melhor entendimento sobre um "patrimônio" indígena. Muito já fora dito sobre a relação entre patrimônio e comunidades locais nas suas diversas matizes (BEZERRA, 2011; 2013; GONZALEZ, 2007; CANCLINI, 1994), mas buscaremos explorar a temática da ancestralidade como um dos componentes chaves para entender a relação entre patrimônio e alteridades culturais, pois entendemos que tal perspectiva tem sido pouco explorada.

Tendo como enfoque alguns exemplos etnográficos e, em especial, a relação que os Hupd'äh desenvolvem com a noção de /hib'ah tẽh d'äh/, “ancestrais", procuraremos demonstrar as diversas formas que essa ideia/conceito/noção de ancestralidade acarreta. As viagens aos lugares sagrados feitas junto com interlocutores da comunidade Hupd'äh de /Tat dëh/ revelaram práticas e modos de percepção profundamente relacionados àqueles dos momentos ritualísticos das 'rodas de coca', encontros noturnos de anciões para narrar mitos e realizar curas e proteções xamânicas. Durante as caminhadas, as interações com animais através da caça e da pesca, com os diversos seres míticos e paisagens demonstraram a necessidade de uma reflexão sobre os modos de percepção do ambiente vinculados a uma noção abrangente de ancestralidade. Isso fora feito tendo como baliza teórica as abordagens relacionalistas de Gow (2001), Ingold (2000) e Houseman e Severi (2009) para enfocar a continuidade histórica que mescla diversos pontos de referência de ancestralidade. A partir 
dessa perspectiva, procuramos interpretar o narrar e o benzer como modos de ação que mobilizam sensorial e experiencialmente os participantes, permitindo a interação com diversos seres e ambientes para a atuação em processos de transformação no mundo.

\section{Ancestralidade}

Pode-se dizer que a imagem de um ancestral é algo recorrentemente associado a princípios de descendência nas mais diferentes culturas humanas. A própria palavra derivada do latim ANTECEDERE - "preceder, vir antes"- traz em si essa ideia de descendência. No entanto, é importante ressaltar que esse tom de descendência (ou ascendência) é mais forte em algumas culturas do que outras. Não, necessariamente, outras culturas compartilham da mesma lógica. Por exemplo, Taylor (1998) demonstra essa variabilidade conceitual do tema da ancestralidade entre os Jivaro no Peru amazônico:

[...]Par ailleurs, les restes archéologiques qui jonchent l'habitat jivaro ne sont jamais attribués à des ancêtres mais à des êtres mythiques dits iwianch, géants cannibales sans rapport avec l'humanité présente. Les tribus jivaro disparues - qu'on connaît par les archives - n'apparaissent enfin qu'en de brèves et rarissimes épiphanies, sous les espèces de guerriers splendidement vêtus, marchant à l'envers et parlant en sifflant, qui s'évanouissent au moindre soupçon de présence humaine, de témoin contemporain. (TAYLOR, 1998: 03) ${ }^{3}$.

Na década de 1970 e 1980, os modelos de etnologia africana eram especialmente criticados pelos exemplos ameríndios, principalmente em contraste com as noções de ancestralidade vinculadas ao mundo dos mortos (CARNEIRO DA CUNHA, 1977). Nesse sentido, explorando os contrastes apontados por Pierre Clastres em relação ao mundo andino, Philippe Erikson (2007) enfoca as matizes de significado que o termo "ancestral" adquire nas máscaras do grupo Matis (Pano), na bacia amazônica:

In the light of new fieldwork material, my aim in the following pages is to provide a closer definition of what "ancestral" means in this Amazonian context. More precisely, I intend to show that the mariwin achieve the paradoxical feat of embodying values associated with ancestrality while nonetheless being denied the status of kin, since discourses and practices connected to them ostensibly reject the idea of filiation per se (2007: 219).

\footnotetext{
${ }^{3}$ Por outro lado, os restos arqueológicos encontrados no habitat dos jivaros nunca são atribuídos aos seus ancestrais, mas a entidades míticas conhecidas como iwianch, gigantes canibais sem nenhuma relação com a humanidade presente. As tribos jivaro desparecidas - que conhecemos pelos arquivos- aparecem enfim em breves e raríssimas epifanias, são uma espécie de guerreiros maravilhosamente vestidos, que caminham ao contrário e falam assoviando, e que desaparecem na mínima desconfiança de presença humana contemporânea (trad. nossa).
} 
Para além do debate antropológico, não podemos desconsiderar que a arqueologia se baseia fortemente em certas noções de ancestralidade e que isso tem gerado conflitos. Antes de prosseguir, é importante pontuar que esse artigo segue a percepção da importância do contato da arqueologia com comunidades tradicionais. Numa abordagem reflexiva, esse contato é a porta de entrada para novos horizontes epistemológicos (GNECCO Y AYALA, 2011). Sem desqualificar tal ciência enquanto disciplina, essa abertura enriquece o seu repertório (PYBURN, 2005). Bezerra aponta esta relação tensa a respeito de patrimônio:

Ou seja, o paradoxo está no fato de que o conceito de patrimônio (sítios e objetos arqueológicos) é fortemente alicerçado na materialidade e na sua duração no tempo. Constitui, portanto, uma perspectiva histórica, que desconsidera a dinâmica e a lógica memorial de construção do passado pelos indígenas (BEZERRA, 2012: 77).

É justamente essa perspectiva histórica da disciplina arqueológica, fortemente calcada na noção de ancestralidade, que se torna a base das epistemes (ALBERTI, BENJAMIN et al., 2011) do dado arqueológico. A relação de ancestralidade é um dos principais debates na arqueologia, principalmente quando nos referíamos à continuidade/descontinuidade étnica na história indígena (EREMITES DE OLIVEIRA, 2007; NEVES, 1998).

Tal debate se encontra especialmente aprofundado na reflexão da etnoarqueologia enquanto campo de pesquisa arqueológica/antropológica, como demonstra Silva (2009) ao traçar o panorama histórico da questão. Nas palavras de Silva (2009):

A etnoarqueologia deixa de ser uma abordagem arqueológica voltada, exclusivamente, à compreensão das populações no passado, para se transformar em uma possibilidade de entender as populações do presente em termos de suas relações com a natureza e a sobrenatureza (SILVA, 2009: 35).

No entanto, o tema da ancestralidade, neste aspecto, toma sua forma mais explicita quando observamos os contextos pós-processuais da etnoarqueologia. Pode-se dizer que observar não só um contexto ontológico da disciplina arqueológica (POUGET, 2010), como também seu contexto de análise etnográfico junto à 'cultura material' vem mostrando-se cada vez mais relevante para as pesquisas nessa área.

\section{O contexto etnográfico}

Os Hupd'äh habitam a região do Alto Rio Negro (AM) na fronteira entre o Brasil e a Colômbia. Suas comunidades situam-se às margens de igarapés da área interfluvial dos rios Tiquié e Papuri, afluentes da margem esquerda do rio Uaupés. Os dados demográficos mais 
atuais estimam a população num total de 1.500 indivíduos distribuídos em aproximadamente 35 aldeias (ATHIAS, 2006; EPPS, 2005). A alta mobilidade e circulação pelo território são aspectos fundamentais do modo de vida hup relacionados ao vasto conhecimento que possuem sobre os caminhos, igarapés, animais e vegetação local.

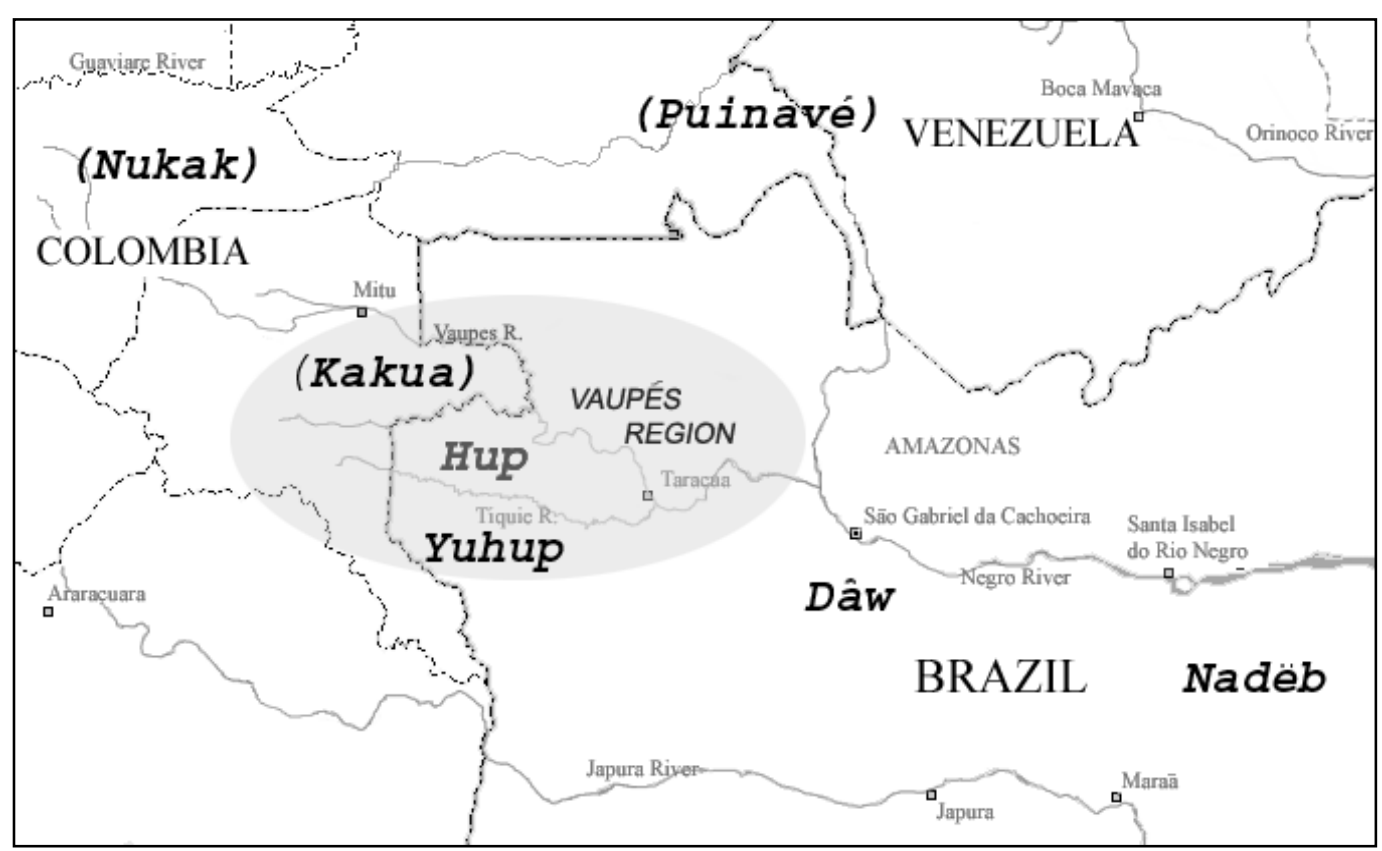

Fig. 1: Localização dos povos falantes de línguas da família Nadahup (Maku) e da comunidade de Taracuá Igarapé onde se realiza a maior parte das atividades de pesquisa. Fonte: EPPS, Petience. A grammar of Hup. Dissertation. 2005.

A estrutura social hup tem nos clãs agnáticos seus segmentos básicos de constituição e de diferenciação. Criados pelo herói cultural /K'ẹg-Tệh/, os “ancestrais”, /Hib'ạh-Tệh-d'äh/, deram origem aos hoje aproximadamente 20 clãs patrilineares, exogâmicos e de descendência unilinear. Cada clã possui um conjunto específico de nomes, mitos e cantos através dos quais são narrados os eventos de criação e se constitui um senso de pertencimento e identidade.

O contato iniciou-se com as frentes de colonização desde o século XVIII, mas foi apenas nas décadas de 60 e 70 do século XX que os missionários salesianos iniciaram atividades mais intensas visando à envangelização e à escolarização dos Hupd'äh. Trabalhando já há décadas com os Tukano, os padres salesianos pretendiam intervir nas relações assimétricas entre esses povos. Nos últimos anos, as atividades das equipes de saúde, de indigenistas, e de missionários pentecostais vêm somando-se à ação dos salesianos que ainda mantêm suas ações em uma aldeia hup e na região do Alto Rio Negro como um todo. 
As viagens realizadas aos morros e lugares sagrados em 2012/2013 tiveram como motivação inicial a elaboração de um 'mapa dos caminhos' que englobariam os antigos assentamentos, caminhos míticos, pisos ecológicos de caça e coleta e marcadores de narrativas êmicas. Foram visitados ao todo oito morros sagrados, duas cachoeiras, cinco moradas antigas e inúmeros espaços que marcam a história dos ancestrais e heróis míticos hup. Foram descritas as técnicas de caça, pesca, as relações jocosas entre os viajantes, a percepção dos espaços, da orientação e do tempo. Em especial, a observação de fragmentos cerâmicos nesses sítios foi interpretada pelos Hupd'äh como restos dos instrumentos de cozinha de 'ancestrais'. Em língua hup, a palavra /hib'ah tẽh d'äh/, "gente do nascimento", revela uma acepção própria da noção de ancestralidade.

Muitos dos caminhos não eram percorridos há décadas. Por isso, foi admirável o interesse de muitos jovens em participarem das caminhadas com adultos e senhores hup. Essas caminhadas conjuntas deram a oportunidade para entender um pouco melhor uma ‘educação da atenção' (INGOLD, 2000) através da qual os mais velhos revelam aos mais novos sentidos que estão no mundo, o que se complementa com a noção de ancestralidade. Nesse sentido: a descrição da viagem à Serra Grande pode ser vista como fundamental. O percurso e banhos rituais realizados no alto da serra ligam-se às práticas xamânicas e aos encontros noturnos para o consumo de coca, as 'rodas de coca', que conjuntamente constituem modos de percepção de ancestralidade. A viagem a essa serra demora aproximadamente uma semana para os moradores de Taracuá-Igarapé. Deve ser feita pelo menos duas vezes por cada pessoa para que se banhem nos lagos sagrados que há no topo do morro. Ao longo das últimas décadas, a prática, também fundamental para a iniciação xamânica, tornou-se menos frequente. Assim, a escalada e chegada ao topo para os banhos foram ações reveladoras sobre uma série de aspectos do modo como os Hupd'äh experienciam o mundo. Para melhor compreender esses modos de ação associados pela viagem aos morros sagrados é necessário explorar o contexto ritualístico das 'rodas de coca'.

\section{Rodas de Coca}

Ao pôr do sol, quando o som do pilão começa a ecoar pela aldeia, é possível acompanhar os passos dos senhores hup que vão caminhando vagarosamente, saudando-se e sentando-se em seus bancos para formar as rodas de coca. Enquanto a fumaça dos cigarros tateia os ares noturnos, o pó verde da coca vai sendo derramado nas bocas. Em meio às conversas, histórias começam a ser contadas, encantamentos são ensinados e andanças pelos 
caminhos da mata são comentadas. Murmurando palavras para cigarros ou cuias, alguns dos participantes executam ações xamânicas para curar ou proteger pessoas.

Os encontros noturnos podem ser vistos como um modo de ação que permite aos participantes constituírem percursos de observação a partir de seus próprios movimentos em meio às palavras sopradas dos encantamentos, às narrativas míticas e aos passos trilhados pelos caminhos que atravessam a floresta (INGOLD, 2000; GOW, 2001). Os encontros noturnos vêm sendo tomados como performances, contextos que associam os fazeres míticos e xamânicos a partir de uma forma relacional particular que articula distintas formas de mobilidade e de interação ${ }^{4}$. Ao longo da pesquisa, percebeu-se que os modos de ação articulados pelas rodas ocorrem por meio da mobilidade específica das viagens. Essas viagens são tanto as caminhadas para banhos e ingestão de água das serras, tidas como moradas de 'ancestrais', quanto os deslocamentos da pessoa ao benzer ou sonhar para as casas cósmicas do céu, do rio, da terra, onde habitam 'ancestrais' e seres como o Trovão, as Gentes-Onça, as Gentes-Cobra, dentre outros.

Contando sobre os 'ancestrais', viajando rumo às serras ou aos planos-casa, os senhores hup atuam na passagem entre contextos, na transição entre estados, na transformação de pessoas e de perspectivas. Nesse sentido, a abordagem processual de Turner (1967) ajuda a perceber como nesses deslocamentos ao longo do mundo ocorrem transições e metamorfoses entre (betwixt and beetween) tempos e espaços.

Apenas dessa maneira é possível atentar à configuração de uma memória ritual que se dá na recordação e no esquecimento, entendidos como atos de percepção das mudanças criadas, experienciadas, sofridas, desejadas e temidas ao longo da vida das pessoas hup (SEVERI, 1996; GOW, 2001). As rodas situam processos de educação da atenção em que o contar e benzer são vistos como atos de mostrar sentidos que então no mundo e que consolidam a longa história de interações dos Hupd'äh com os diversos seres: 'ancestrais', espíritos, animais, pessoas de outras etnias e, mais recentemente, Brancos com quem cohabitam. A atenção aos gestos do preparo da coca, às posturas corporais, aos atos de palavra, aos modos de deslocar-se em benzimento ou pelos caminhos que revelam a memória ritual

\footnotetext{
${ }^{4}$ As breves observações feitas pelos pesquisadores do Noroeste Amazônico sobre as práticas da coca até o trabalho de Hugh-Jones (1995) explicitam certa invisibilidade desse modo de sociabilidade na literatura etnológica. No entanto, as rodas de coca situam, noite após noite, uma dinâmica constante de interações por meio da articulação característica de relações (HOUSEMAN \& SEVERI, 2009: 182). Ao acompanhar o narrar, o benzer e o sonhar como uma sequência articulada de modos de ação dos encontros noturnos abre-se a possibilidade de seguir a organização da ação performática nela mesma (idem: 208) através não da exegese total de um ritual, mas das múltiplas condensações rituais que associam esses modos de relação.
} 
como um processo de engajamento perceptual com o ambiente para interações reflexivas (INGOLD, 2000).

\section{Os lugares Sagrados - o caminho das nuvens}

Às vésperas de nossa viagem às serras para pescar e visitar os lugares sagrados, a chuva insistia em cair. Parecia mais forte a cada dia. No final da tarde, as tempestades invadiam a aldeia com suas águas, ventos fortes e relâmpagos que dificultavam a realização das rodas de coca e adiavam nossa caminhada.

Foi, então, que uma massa de nuvens negras formou-se no céu quando estávamos sentados em roda. Com toda a força de suas águas e ventos, a tempestade vinha em direção da aldeia. Os estrondos dos trovões e a claridade dos relâmpagos assustavam a todos. Ponciano parou de falar. Começou a soprar um cigarro. Os lábios pronunciavam palavras silenciosas. Num dado momento, acendeu o fumo e se levantou. Tragou. Fechou sua mão direita e levou-a para perto da boca. Os olhos parados nas nuvens negras que se aproximavam. Um sopro vindo do peito lançou a fumaça para fora do corpo. Ao mesmo tempo, Ponciano arremessou com força sua mão e seu braço para longe e fez com que a tempestade rumasse por outro caminho para a /Dëh K'et-Yoh-Mọy/, a "Casa-da-Cabeceira”.

Depois, o benzedor sentou-se novamente. Retomou seu lugar à roda. Queria contarme como se realiza esse /Dëh bi'ịd/, "benzimento da chuva", que faz com que as nuvens se afastem para outro caminho no céu e não despejem suas águas, raios e trovões sobre a aldeia.

\section{B1. /Sọ̃h tạ' bi'ịd/ - Benzimento para cercar a chuva/ inverno}

Você fala o nome de /Mu'se'/, aquele da bíblia. Você se levanta e abre os braços como ele fez para abrir o Mar Vermelho. Como ele, você afasta as águas para as cabeceiras.

\section{B2. /Sọ̃h tạ' bi’ịd/ - Benzimento para cercar a chuva/ inverno}

Lê-se a tartaruga vermelha e sua canoa. A tartaruga preta e sua canoa. Fala-se para ela colocar todas as suas coisas em sua casa, dentro de sua canoa, e ir nadando até a cabeceira. Seu nado, o movimento de suas nadadeiras vai separando a água. Como Moisés quando separou as águas. Isso vai cercando a água também. Fala-se para suas /dëh hup hệh/, para suas coisas/armas. Fala-se para sua /hẽy b’ạh/, sua tesoura da origem. Então, conforme ela vai nadando ela afasta a água da chuva e cerca. 
As nuvens afastaram-se logo depois que ele realizou o ato de benzimento e recebeu o olhar de aprovação e reconhecimento de seus companheiros. Em seguida, sentou-se e começou a contar os encantamentos. Em pé com o corpo voltado para as nuvens que se aproximavam, o velho Ponciano evocava as ações de Moisés e das tartarugas. Seus gestos fizeram com que a fumaça que saía de sua boca fosse lançada em direção às nuvens. Ao jogar seu braço, fez com que elas rumassem para a "Casa-da-Cabeceira".

$\mathrm{Na}$ relação que se estabelece com as nuvens ocorre uma interação entre uma fumaça terrestre e uma fumaça celeste. O benzedor imitava o nado da tartaruga abrindo os braços e espalhando o ar à sua frente. Moisés abriu o Mar Vermelho. Estendeu a mão e Javé fez soprar um vento oriental muito forte que perdurou a noite inteira e dividiu as águas em duas. Lançando o braço à frente, Ponciano imitava o ancestral dos Brancos. A coluna de nuvens que acompanhava o "povo de deus" retirou-se da frente deles e colocou-se atrás. Assim, o "povo de deus" pôde seguir, atravessando o Mar Vermelho com os "pés enxutos". Continuaram pelo caminho indicado por Javé, que os levaria ao Monte Sinai e à Terra Prometida, onde corre leite e mel. Pela manhã, quando os soldados egípcios atravessavam o mar aberto, Javé fez as colunas de água desabar sobre eles, aniquilando-os completamente (Ex. 3,14; 4,33; 1990a).

Para que pudéssemos viajar para os morros e para as Moradas Antigas, o xamã alterou o rumo das nuvens da tempestade para a cabeceira, fazendo com que os caminhos alagados secassem.

\begin{tabular}{|c|c|c|c|}
\hline \multicolumn{4}{|c|}{ Modos de ação correlacionados } \\
\hline $\begin{array}{ll}\text { Um } & \\
\text { profeta }\end{array}$ & \begin{tabular}{|l} 
ergue \\
braço
\end{tabular} & $\begin{array}{l}\text { divide } o \\
\text { mar }\end{array}$ & $\begin{array}{l}\text { afasta } \\
\text { as nuvens para } \\
\text { a retaguarda }\end{array}$ \\
\hline $\begin{array}{r}\text { A } \\
\text { tartaruga }\end{array}$ & Nada & $\begin{array}{l}\text { separa } \\
\text { as águas }\end{array}$ & $\begin{array}{l}\text { afasta } \\
\text { as nuvens para } \\
\text { a cabeceira }\end{array}$ \\
\hline $\begin{array}{l}\text { Um } \\
\text { benzedor }\end{array}$ & $\begin{array}{ll} & \text { lança } \\
\text { braço } & \end{array}$ & $\begin{array}{ll}\text { sopra a } \\
\text { fumaça }\end{array}$ & $\begin{array}{l}\text { afasta } \\
\text { as nuvens para } \\
\text { a cabeceira }\end{array}$ \\
\hline
\end{tabular}

Fig. 2: Quadro comparativo de ações 
As ações do benzedor, do profeta e da tartaruga geram mudanças num dado ambiente com o qual se relacionam. De modo muito interessante, a viagem de Moisés e seu povo rumo à Terra Prometida parece ser uma transformação da viagem da tartaruga com destino à Casada-Cabeceira. Soprando esses modos de ação para o cigarro, o deslocamento da fumaça e o movimento corporal alteram o destino da tempestade.

A chamada tartaruga-da-amazônia (podocnemis expansa) é considerada a maior tartaruga de água doce da América do Sul, chegando a medir $70 \mathrm{~cm}$ e a pesar $25 \mathrm{~kg}$. Sua coloração varia entre o marrom, o verde e o cinza-oliva. Ela habita as áreas de floresta alagada durante as cheias e migra no período das secas para os corpos de água principais (rios, lagos, paranás, ressacas), em busca de praias para desovar. A /mih-pög/ que encontramos nessa Casa-de-Pedra estava possivelmente abrigando-se na caverna. Protegida de seus predadores nessa morada hup ancestral, a tartaruga estava no mesmo lugar para onde o xamã havia orientado seu deslocamento, a cabeceira de um rio. Na linguagem dos benzimentos, as nadadeiras da tartaruga são ao mesmo tempo remos, /hẹ̃y'-b'ah/, e tesouras/lâminas, /hẹy' b'ah/.

Para a tartaruga convergem percepções simultâneas sobre a mobilidade e a permanência que a tornam uma espécie de ser movediço na acepção que Deleuze e Guattari (1995) dão ao termo. Partindo da reflexão de Ingold (2000: 127), entendemos que na prática dos benzimentos haja a articulação entre um modo totêmico, com a ênfase em aspectos da morfologia e anatomia, e a um modo anímico, com a ênfase no movimento, postura e comportamento dos seres. Desse modo, a tartaruga que tem em seu casco um abrigo e uma canoa pode ser vista como um ser especialmente interessante por condensar em si, em seu corpo, a morada e o meio de transporte. De modo singular, ela está dentro e fora de sua casa, em sua morada e nos caminhos a todo instante. Enquanto o anfíbio navega em sua casa, os Hupd'äh caminham sobre uma canoa. O Povo de Deus, por sua vez, viaja sem casa rumo à Terra Prometida e atravessa o Mar Vermelho sem canoa, com os pés enxutos.

\section{As Analogias Ancestrais}

Pensando com Carneiro da Cunha (1998), B1 pode ser tomada como uma tradução xamânica de B2, possivelmente elaborada após a consolidação dos "povoados-missão" como a aldeia de Taracuá-Igarapé e da participação nas missas, das escolas salesianas, dos batismos que foram situando os Hupd'äh num processo de evangelização já em curso com outros povos da região. Como o Povo de Israel, eles viajavam para terras distantes, para longe das 
cabeceiras, das /Paç-Moy/, "Casas-de-Pedra", próximas às quais seus ancestrais procuraram sempre constituir suas moradas.

De acordo com Reid (1979), antes de 1890 e até 1950, os Hupd'äh viviam na região das cabeceiras dos igarapés ao longo dos quais se encontram as aldeias atuais, situadas em áreas mais próximas aos grandes rios. Entretanto, a violência posta em prática com o "boom da borracha" (1890 a 1900) e com a atuação dos representantes governamentais (Manducas) ${ }^{5}$ teria levado os Tukanos a deixarem a área ribeirinha para fixarem-se em aldeamentos nas áreas florestais, a algumas horas de caminhada. Segundo Reid (1979), esse deslocamento populacional tukano levou as comunidades hup a afastarem-se para áreas ainda mais próximas às cabeceiras. Como visto, durante a viagem à Serra Grande, os espaços da morte povoam a região trazendo lembranças dos confrontos e das vítimas. Os representantes governamentais, os exploradores de borracha e mesmo os Tukanos muitas vezes atacavam as aldeias hup para assassinar e escravizar pessoas (REID, 1979: 25 - 26).

Nos ano 40, ocorreu a aproximação dos salesianos, muitas vezes mediada pelos Tukanos. Os missionários balizavam seu "projeto civilizatório" no aprendizado do português, na moradia em casas nucleares e na conversão cristã, além de condenarem a ação dos exploradores de borracha.

À luz da analogia bíblica, esse movimento migratório para as cabeceiras assemelhase ao Êxodo, uma fuga da perseguição dos soldados egípcios. O paralelo entre os percursos e os sentidos dos deslocamentos desses vários agentes dos encantamentos torna-se interessante para entender o processo histórico que levou à constituição da grande aldeia de TaracuáIgarapé, /Tạt-Dëh/.

Surpreendentemente, o Êxodo até o Mar Vermelho e a migração dos Hupd'äh para as imediações do rio Tiquié são deslocamentos populacionais que se dão no sentido N.O. $\square$ S.E. Na leitura xamânica hup do texto bíblico, Moisés desloca as nuvens para trás, para as cabeceiras, distanciando-as do Mar Vermelho assim como as nascentes estão do rio Tiquié. No mesmo eixo, a viagem que faríamos aos lugares sagrados, o percurso da tartaruga em B2 e o afastamento das nuvens estabelecem-se no sentido inverso S.E. $\square$ N.O. Caminhando, iríamos abrir as trilhas fechadas pela floresta e pelo tempo. Nossa jornada aos "lugares sagrados" constituir-se-ia ao mesmo tempo de atos de relembra dos mentores que visitariam os lugares onde cresceram e conviveram com seus pais e avós, e de percursos de observação

\footnotetext{
5 Wright (2005: 213) comenta que Manuel Albuquerque, o "Manduca", fora um brasileiro mestiço que ocupou o posto de subprefeito de São Gabriel obtido no auge do boom da borracha. Com a ajuda dos irmãos, ele controlava o trabalho indígena por meio da violência e terror.
} 
ao longo dos quais os jovens conheceriam histórias e seres através de seus próprios movimentos e ações e por meio das indicações e narrativas dos mais velhos.

Atentos às histórias e à convivência com os antepassados nesses lugares, movíamonos de um lugar a outro dentro de uma região de memórias. Segundo Ingold (2000):

\begin{abstract}
Likewise, every 'somewhere' is not a location in space, but a position on a path of movement, one of the matrix of paths comprising the region as a whole. In short, whereas everywhere-as-space is the world as it is imagined from a point of view above and beyond, everywhere-as-region is the world as it is experienced by an inhabitant journeying from place to place along a way of life (INGOLD, 2000: 227).
\end{abstract}

A cada passo, os caminhos fechados iam tornando-se caminhos vividos, ou como formula Ingold (2000), percursos de observação nos quais nos posicionávamos pelo itinerário contínuo de nossos movimentos. Atentos ao entorno, os jovens ouviam seus guias e os sons da mata voltavam-se para olhar atentamente quaisquer plantas, animais, paisagens mostradas pelos mais velhos. Percebendo o ambiente a partir de todos os lugares, os saberes iam sendo gerados em campos de prática que faziam convergir eventos da viagem xamânica das "rodas de coca" com situações ocorridas durante o percurso (Ingold, 2000: 226).

\title{
O caminho do "povo de deus"
}

Segundo Athias (1995) (2006), foi apenas nas décadas de 60 e 70 que os missionários salesianos iniciaram atividades mais intensas para evangelizar e transformar o que entendiam ser o "modo tradicional de vida" dos Hupd'äh. Reid (1979: 28) sustenta que, no final dos anos 40 e ao longo dos anos 50, iniciou-se o processo migratório que levou as aldeias hup a afastar-se da região das cabeceiras (inter-flúvios) e começarem a fixar-se nas áreas próximas aos grandes rios e às aldeias tukano e desano.

Ao mesmo tempo, suponho que a atenção para as histórias dos ancestrais dos Brancos, num contexto marcado pela ação missionária e pelas orações e histórias bíblicas, tenha sido fundamental para muitos da geração de Ponciano. A bíblia e o velho testamento trazem outros ancestrais, outros poderes, outros ambientes e outros tipos de ação característicos dos Brancos. A exegese do benzimento (B1) é também uma hermenêutica do texto bíblico, feita por pessoas que observam os missionários, seus ancestrais e suas ações. Imitando-os, mobilizam para si poderes desses Outros e ampliam suas possibilidades de ação no ambiente ribeirinho que passaram a habitar.

De forma semelhante, o convívio com os padres e as freiras permite a compreensão de aspectos do modo de vida e comportamento dos Brancos. A aversão ao "roubo" faz, por 
exemplo, com que ao roubar os Hupd'äh afastem os missionários e riam deles. $\mathrm{O}$ casamento das noviças indígenas causa a ira do padre e permite que as moças retornem às suas vidas conjugais. O riso evidencia o aparente poder de subversão da ação missionária que os antigos hup possuíam, sendo capazes de atrair e afastar os religiosos como quem afasta as nuvens de uma tempestade.

As ações do benzimento parecem correlacionar agências de seres que ocupam lugares estruturais semelhantes. Observando e imitando a ação de Moisés, Ponciano realiza uma hermenêutica do texto bíblico e, ao mesmo tempo, faz com que o ancestral dos Brancos, abrindo o Mar Vermelho, afaste as nuvens negras para trás, para a retaguarda, para a Casa-daCabeceira, para que o "povo hup" possa caminhar rumo aos "lugares sagrados".

Os caminhos antigos, as Casas-de-Pedra e as Moradas Antigas parecem apontar, como já afirmava Reid (1979), para uma existência social e convívio de longa duração nessas regiões. Há semelhança entre os itinerários dos 'ancestrais' e àqueles dos pais e avós dos viajantes hup. A identificação de tantos assentamentos, lugares sagrados, artefatos, a reabertura de caminhos antigos, somadas às descrições das práticas rituais nas Casas-dePedra, revelam as cabeceiras como pontos de referência para os padrões de mobilidade hup. Os caminhos dos antigos eram também os caminhos dos 'ancestrais' que mudavam periodicamente suas moradas dos arredores de um morro ao outro.

\section{Considerações finais}

Os atos de relembrar do xamã constituíam-se, portanto, como percursos de observação, como caminhos vividos que mesclavam seus movimentos àqueles dos 'ancestrais'. É no percurso entre as rodas de coca, os caminhos sagrados e as Casas-de-Pedra, movendo-se com o corpo, com a pessoa-sopro ou com a roupa, que múltiplas condensações rituais ocorrem a partir do modo como os viajantes se posicionam num campo de rastros deixados pelos ancestrais, presas, feras, Brancos, etc. (DELEUZE \& GUATTARI, 1995: 60). Assim, a tartaruga é nódulo de representação com a qualidade de 'ser movediço' na acepção que Deleuze e Guattari (1995) dão ao termo, que seria o elemento aglutinador de novos elementos de ancestralidade (como Moisés) na ordem cosmológica. Tal nódulo aglutinador, portanto, também fornece sentido êmico incorporando a narrativa bíblica na visão de mundo Hupd'äh.

Retomando a discussão inicial sobre patrimônio, Coelho de Souza (2010) faz a seguinte consideração sobre o aspecto temporal, em especial o da ancestralidade, baseado no 
contexto etnográfico dos Piro - com o qual podemos fazer um paralelo com o contexto Hupd'äh apresentado acima:

\begin{abstract}
Se a memória dos cuidados entre pessoas é o que constitui as relações de parentesco e a sociabilidade piro (GOW, 1991), o cultivo de uma tal memória após a morte é terrivelmente perigoso, e os Piro, como virtualmente todos os ameríndios, procedem a um esforço deliberado de esquecimento dos que morreram, do qual a destruição ostensiva dos pertences dos mortos é um dos aspectos mais evidentes. E, no entanto, os ensinamentos, os "costumes dos antigos", continuam sendo mantidos vivos. Como? Como conhecimento - inscrito no corpo - dos vivos (COELHO DE SOUZA, 2010: 154).
\end{abstract}

Assim, temos além dos já clássicos embates entre diversas noções de patrimônio (Revista do Patrimônio, 2012, N34-IPHAN) há uma maior aproximação com a crítica do ‘tradicionalismo' vinculado ao patrimônio, assim explicada por Garcia Canclini:

Para radicalizar essa dessubstancialização do conceito de patrimônio nacional é necessário questionar essa hipótese central do tradicionalismo, segundo o qual a identidade cultural se apoia em um patrimônio constituído através de dois movimentos: a ocupação de um território e a formação de coleções (2006: 190).

Portanto, ter em conta os aspectos ocidentais de patrimônio e ancestralidade, faz parte de uma prática não só teórica de uma arqueologia, como também de valorização prática de referenciais nativos. Isso incentiva o interesse das populações locais sobre o tema de patrimônio, ampliando a sua definição - ele se torna histórico e apoiado em múltiplas visões de mundo. É nesse sentido que Gnecco e Ayala (2011: 26) fazem a seguinte afirmação: "Se o desentendimento indígena por 'coisas arqueológicas' não é um ponto de partida e sim um assunto que pede para ser interpretado, também o é o desdém dos arqueólogos por outras histórias contadas, que merece atenção analítica".

Assim, a abordagem Hupd'äh sobre ancestralidade demonstra o interesse sobre o patrimônio arqueológico, associando-o a explicações cosmológicas e ontológicas extremamente complexas. E tal conciliação de interpretações - científica e êmica - deve ser feita levando em consideração a crítica da autoimagem de ciência arqueológica. A complexificação da noção de 'ancestral' é apenas um dos caminhos possíveis nessa busca pelo diálogo entre categorias acadêmicas e ontologias ameríndias. Muitos outros caminhos se farão presentes se refletirmos colaborativamente - pesquisadores e interlocutores - para própria construção das epistemes e dos modos de percepção e ação. 


\section{Referências bibliográficas}

ALBERTI, Benjamin et al. "Worlds Otherwise: Archaeology, Anthropology, and Ontological Difference”. Current Anthropology, 52.6 p. 896-912. 2011

ATHIAS, Renato. Hupdah-Maku/Tukano: les rélations inègales entre deux societés du Uaupés Amazonien (Brésil). Tese. Doutorado em Antropologia. Université de Paris X Nanterre, Paris. 1995.

Os Hupd'äh. In. RAMIREZ, Henri. A Língua dos Hupd'äh do Alto Rio Negro. São Paulo, ed. Associação Saúde Sem Limites, 2006.

BENJAMIN, Walter. "The Work of Art in the Age of Mechanical Reproduction." In Illuminations (Trans. Harry Zohn), edited by W. Benjamin, p.217-251. London: Fontana. 1992

BEZERRA, Marcia. "Um breve ensaio sobre patrimônio arqueológico e povos indígenas". Revista da SAB. v. 24, n 2 DEZEMBRO, v. 24, n. 1, p. 74-85. 2011.

"Os Sentidos Contemporâneos Das Coisas Do Passado: Reflexões A Partir Da Amazônia”. Revista de Arqueologia Pública, Campinas, nº 7, julho 2013.

BÍBLIA, Livro Êxodo. Bíblia Sagrada. Edição Pastoral, São Paulo, ed. Paulus, 1990a.

BINFORD, L. R. "Methodological considerations of the archaeological use of ethnographic data”. In: LEE, R. B.; DEVORE, I. (Eds.). Man the Hunter. New York: Aldine:p.268-273. 1968

"Smudge pits and hide smoking: the use of analogy in archaeological reasoning". American Antiquity, v. 32, n 1:p.1-12, 1967

CANCLINI, N. G.. "O Patrimônio Cultural e a Construção Imaginária do Nacional”. Revista do Patrimônio Histórico e Artístico Nacional, 23: p.94-115. 1994.

CARNEIRO DA CUNHA, Manuela. "Pontos de vista sobre a floresta amazônica". Revista Mana. Museu Nacional, Rio de Janeiro. Vol.4 n 1. p. 23-45, 1998.

CARNEIRO DA CUNHA, Manuela . "Espace funéraire, eschatologie et culte des ancêtres: encore le probléme des paradigmes africains". In: Societé International des Américanistes. (Org.). Actes du LLéme Congrès International des Américanistes. Paris: CNRS, v. 2, p. 276295. 1976

COELHO DE SOUZA, Marcela. "A cultura invisível: conhecimento indígena e patrimônio imaterial”. In: Anuário Antropológico/2009, Brasília, v. 1 :149-174, 2010.

DELEUZE.G. \& GUATTARI, F. Mil platôs. Vol 1. São Paulo, Ed. 34, 1995. 
EPPS, Petience. A grammar of Hup. 2005. 799 f. Ph.D Dissertation -Linguistic anthropology. University of Virginia and Max Planck Institute for Evolutionary Anthropology. Virginia. 2005.

EREMITES DE OLIVEIRA, J. "Cultura material e identidade étnica na arqueologia brasileira: um estudo por ocasião da discussão sobre a tradicionalidade da ocupação kaiowá da Terra Indígena Sucuri'y". Revista de Arqueologia (Sociedade de Arqueologia Brasileira. Impresso), v. 19: 29-50, 2007.

ERIKSON, Philippe. "Faces from the Past. Just how'Ancestral'are Matis' Ancestor Spirit'Masks?", In Time and Memory in Indigenous Amazonia. Anthropological Perspectives. FAUSTO, Carlos \& HECKENBERGER, Michael. Gainesville: University Press of Florida, p. 219-242, 2007.

FAUSTO, Carlos \& HECKENBERGER, Michael. (Eds.)Time and Memory in indigenous Amazonia: anthropological perspectives. University Press of Florida, 2007.

GNECCO, C. \& AYALA, P. (Eds.) Indigenous Peoples and Archaeology in Latin America. Left Coast Press, 2011.

GONÇALVES, J.R. 2003. "O Espírito e a Matéria: o patrimônio como categoria de pensamento". Habitus, v. 1, n 2:459-468, 2003.

GOW, Peter. An Amazonian myth and its history. New York, Oxford University Press, 2001.

HODDER, I. The present past. NewYork, Pica Press, 1982.

HOUSEMAN, Michael \& SEVERI, Carlo. Naven ou le donner à voir Essai d'Interprétation de l'Action Rituelle. Paris: CNRS-Éditions, 2009.

HUGH-JONES. S. "Coca, Beer, Cigars and Yagé”. In: GOODMAN, J.; LOVEJOY, P. \& SHERRAT, A. (org.). Consuming Habits: Drugs in History and Anthropology. New York, Routledge, p. 47-66.1995.

INGOLD, Tim. The perception of the environment. London, Routledge, 2000.

LYDON, Jane; RIZVI, Uzma Z. (Ed.). Handbook of postcolonial archaeology, New York. Left Coast Press. 2010.

MYERS, F. R. "Ancestral Connections: Art and an Aboriginal System of Knowledge. Howard Morphy- Review”. American Ethnologist, 22: 1040-1041. 1995.

NEVES, Eduardo G. "A Arqueologia na Antropologia Brasileira: História Indígena sem Paleoetnografias Passado". ANPOCS, 1998.

POUGET, F. M. C. Práticas arqueológicas e alteridades indígenas. 2010. Dissertação de Mestrado. Museu de Arqueologia e Etnologia, Universidade de São Paulo, São Paulo. 2010.

PYBURN, K. A. “Why Archaeology Must Be a Science”. Habitus, 3 (2): 221-240, 2005. 
REID, Howard. Some aspects of movement, growth and change among the Hupdu Maku Indians of Brazil. . 1979. Dissertation. Faculty of Archaeology and Anthropology, University of Cambridge. . 1979

SEVERI, Carlo. La memoria ritual. Castilla, Ediciones Abya-Yala, 1996.

SILVA, Fabíola A. "Etnoarqueologia: uma perspectiva arqueológicapara o estudo da cultura material". MÉTIS: história \& cultura, v. 8, nº 16, jul./dez. 2009.

TAYLOR, Anne C. "L'oubli des morts et la mémoire des meurtres: expériences de l'histoire chez les Jivaro", Terrain, Paris, n 28, 1998.

TURNER, Victor. The forest of symbols: aspects of Ndembu ritual. Ithaca: Cornell University Press, 1967.

O processo ritual: estrutura e anti-estrutura. Petrópolis: Vozes, 1974.

Publications, 1982.

From ritual to theatre: the human seriousness of play. New York: PAJ The anthropology of performance. New York: PAJ Publications, 1988.

SCHOUTEN, André-Kées. Do estruturalismo ao perspectivismo, uma história de vencedores nas terras baixas sul americanas. 2010. [no prelo]

WRIGHT, Robin. História indígena e do indigenismo no Alto Rio Negro. São Paulo, ed. ISA/ Mercado das Letras, 2005. 